Intersections

Canadian Journal of Music

Revue canadienne de musique
Intersections

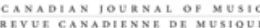

\title{
Local Logics and the Gendering of Music Technology: A Newfoundland Case Study
}

\section{Beverley Diamond}

Volume 26, numéro 2, 2006

In and Out of the Sound Studio

URI : https://id.erudit.org/iderudit/1013225ar

DOI : https://doi.org/10.7202/1013225ar

Aller au sommaire du numéro

Éditeur(s)

Canadian University Music Society / Société de musique des universités canadiennes

ISSN

1911-0146 (imprimé)

1918-512X (numérique)

Découvrir la revue

Citer cet article

Diamond, B. (2006). Local Logics and the Gendering of Music Technology: A Newfoundland Case Study. Intersections, 26(2), 49-68.

https://doi.org/10.7202/1013225ar

Copyright @ C Canadian University Music Society / Société de musique des universités canadiennes, 2007
Ce document est protégé par la loi sur le droit d'auteur. L'utilisation des services d'Érudit (y compris la reproduction) est assujettie à sa politique d'utilisation que vous pouvez consulter en ligne.

https://apropos.erudit.org/fr/usagers/politique-dutilisation/ 


\title{
LOCAL LOGICS AND THE GeNDERING OF MUSIC Technology: A Newfoundland Case Study
}

\author{
Beverley Diamond
}

This paper reports on issues relating to the gendering of music technologies that emerged in recent studies conducted in Newfoundland and Labrador. The primary study was a broad-ranging assessment of the status of women in music that the Women's Policy Office of the Government of Newfoundland and Labrador commissioned from the Research Centre for the Study of Music, Media and Place (MMaP) in the summer of 2005. It was not specifically focused on technology issues although these issues quickly emerged as a priority for many participants. Additionally, several community projects conducted by graduate students on the gendering of music technologies for a Memorial University course taught in the Fall of 2006 are referenced.

I describe how women who self-identified as "technological professionals" and others who claimed little or no technological expertise articulated technology-related challenges and strategies in the context of a thriving province-wide music scene. I ask whether their senses of place influence their perceptions of the issues as well as the strategies they use to resolve the problems they face. Implicitly, the exploration raises questions about the utility of localizing discussions about gender and music technology.

Until recently, music technology was most often heralded as a means of getting out of the local, a means of extending the reach of one's music. As Greene and Porcello state,

Music can no longer be adequately modeled as something that happens in a local context and employs only the expressive means specific to a locality. Instead, music making increasingly employs technologies produced elsewhere and is informed by a heightened awareness of sounds that are traveling rapidly around the world. $(2005,2)$

The articles in their anthology, however, clearly demonstrate that both the discourse and uses of technology are conditioned by local social issues and cultural values, revealing that the "technologies of wired sound also have the potential (whether fully realized or not) of opening up new directions for musical expression and evolution, inspiring new logics of music creation and empowering local cultural and expressive values" $(2005,3)$. In relation to Newfoundland and Labrador, my questions emerge from the evidence of such recent studies. Have "new logics of music creation" inflected the well documented (Wajcman 1991, Haraway 1991, McCartney 1995a and b, for example) gendering of (music) technologies? How do the "cultural and expressive values" of a specific 
place influence the lives of women who seek to engage with new technologies? Can place be separated from the "inspiration" to find new logics of music creation? Just who is so inspired?

\section{The Research}

As mentioned above, the central project (hereafter called the NL Women and Music Project) underpinning this paper was a study funded by the provincial government's Women's Policy Office (Ministry Responsible for the Status of Women). That office asked researchers at Memorial University's MMaP Research Centre:

To plan and implement a workshop that would develop a research tool, survey methodology and report requirements to study and disseminate quantitative and qualitative information about the status of women in the music sector. ${ }^{1}$

These instructions were exciting but challenging on several fronts. The definition of "the music sector" was purposely broad, extending well beyond the music industry and the community of "professional" creators and performers. Educators, arts administrators, amateur and semi-professional singers or instrumentalists, community musicians in all ethnocultural communities, children and youth as well as adults, producers and sound engineers-all were included in this broad definition. Furthermore, it was clear from informal discussion that not merely a research tool was expected but a research tool that had been tested along with the preliminary findings of that research "test period." The six-week time frame for the project, then, was a constraint albeit one that we all accepted.

The NL Women and Music Project was overseen by the author and four research assistants from Folklore and Women's Studies at Memorial University. ${ }^{2}$ The research was launched with a one-day "workshop" on May 30, 2005, to which 80 women from all parts of the province were invited and which 55 attended. The invitees were selected by using published lists such as the Directory of the Music Industry Association, and the directory of the NLMusic Teachers Association, but also by relying on a pyramid structure to reach many women who remain outside the provincial music organizations. That is, a number of individuals in diverse regions and musical genre worlds were asked to name a larger number who were again asked to name others and so on. Participants in the workshop represented a wide range of activities (composers, song-writers, performers, administrators, teachers, students, technological experts), genres (classical, traditional, rock, blues, punk, country, South Asian classical, Native American intertribal) and regions (Labrador, Stephenville, Corner Brook,

Maureen Houston (MMaP Research Centre) was administrative coordinator. Kristin Harris, (Folklore), Melanie Lovatt (Folklore), and Lisa Faye (Women's Studies) worked as interviewers and research assistants. 
Grand Falls, Trinity, and the Avalon region) in the province. While ethnocultural diversity was evident, it was proportionately quite small. While students (and indeed teachers) were represented, the scheduling of the workshop after the end of the university term and shortly before the end of the high school year resulted in a somewhat low proportion from both sides of the education sector.

The workshop had no formal presentations but rather a series of organized (large and small) group discussions on (a) factors that participants deemed specific to our location in Newfoundland and Labrador, (b) "thematic" gender issues relating to technology, image, professional development, performance and other work, and (c) "sectoral" gender issues specific to different professional sectors or genre worlds. Thematic questions directly relevant to technology included the following:

- Have you ever been given or denied special opportunities in the course of your professional development?

- How adequately are your equipment needs met in different venues, or non-performance contexts?

- How would you characterize your experiences in recording studios?

- Do you have particular strategies for working with technicians?

More general inquiries into career challenges or dreams of doing more or different things in music also gave rise to technology related discussion.

Sectorally distinct questions addressed to five women who self identified as technology professionals included the following:

- How did you get into the technology field you now work in?

- What challenges have you encountered?

- Do you think you work differently at your profession vis-à-vis your male colleagues?

- If you think the norms of your profession are stereotypically gendered, do you do anything to counter the stereotypic gender norms in your profession?

- What specific challenges are there to getting work and developing a career in the technology-related music sector in NL?

The free form discussions, however, ranged widely.

At the end of the day, participants were asked to identify priority issues. A clear consensus emerged that technology training for women was one such issue.

The particular configuration of workshop participants circumscribed the assumptions and consequent representations that emerged about what constitutes "Newfoundland culture." For instance, the discussion groups often presumed a large measure of homogeneity and shared Anglo-Irish heritage/experience. A South Asian participant got sympathetic nods but no serious discussion when 
she raised culturally specific issues and a second non-European partipant chose to remain silent in most discussions. Furthermore, the category "woman" was seen as diverse but fundamentally unproblematic as a construct. Little consideration of the discursive construction of this category took place. Additionally, sexual orientation was rarely considered.

Workshop participants maintained polarized assumptions about gender constructs in Newfoundland society. Some believed that women are more highly regarded than in many other urban Canadian contexts, partially as a result of the cooperative structures essential to face the challenges of life in small outports and economically disadvantaged towns and cities. Others assumed that the cohesiveness of small communities contributed to a stronger normalization of conventional gender attitudes and to a general conservatism with regard to social change. Undoubtedly both of these opinions are partially true, operating simultaneously in different situations and social contexts.

After the workshop, the project team undertook two kinds of tasks. A general questionnaire (Appendix A) that sought to gather more baseline data about women in music was distributed. The questionnaire was advertised via several radio interviews, and on electronic distribution lists of MusicNL members, Folk Arts Council members, music educators/professors, and large-scale performing organizations such as the Newfoundland Symphony Association. It was also distributed at several meetings, performance venues, and festivals. Seventy-two questionnaires were returned-not quantitatively significant but arguably indicative of patterns that we then probed, qualitatively, in interviews with two dozen musicians and senior officials in local organizations.

The number of women musicians in Newfoundland and Labrador is hard to ascertain. At the time of the study, women comprised roughly $20 \%$ of the 2004 MusicNL Directory listings but informal estimates suggest they may comprise closer to $50 \%$ of the province's professional musicians. Beyond the ever slippery label of "professional," of course, the number of community based men and women who sustain the musical life of their communities is very high but almost impossible to measure. The belief that music is valued and pervasive gives rise to such expressions as "you can't throw a stone in Newfoundland without hitting an accordion player." 3

The chart below, compiled from our survey results, indicates that the voice is the instrument of choice for women. We suspect that a survey of male musicians might show a similar priority given that song is so highly valued in Newfoundland and Labrador, both historically and currently, as a mode of community narration. The long history of balladry in NL that generated, for instance songs of shipwrecks, natural disasters, occupational activities, or classical tales of lost love, continues as contemporary song-writers record their responses to such things as the codfish moratorium (see, e.g., Narvaz), the Ocean Ranger tragedy (Ron Hynes' "Atlantic Blue"), or more mundane daily circumstances such as

3 The turn-out of 989 accordion players at the 2005 Newfoundland and Labrador Folk Festival, in response to a challenge to establish a new record for the Guiness Book of Records indicates the partial truth of such sayings. The turn-out did earn official recognition in the Guiness Book of Records. 
the plight of snow shovellers when the snow banks are high (Christina Smith's "Snow-shovellers Waltz").

Notable is the fact that female keyboard players are not as numerous as expected. ${ }^{4} \mathrm{~A}$ probable reason for this is a provincially distinctive practice for traditional music. Unlike other Atlantic provinces where keyboards are preferred to accompany fiddles, in Newfoundland, they are virtually never used as fiddle accompaniment. Guitars are commonplace at present (usually said to be introduced by the Scandinavian revivalist singer Omar Blondahl in the 1950s), but historically the unaccompanied melodic line seems to have been preferred. Even accordion players who have the capacity to add some harmony, often prefer to play the melody with no harmonic support. The rarity of keyboards is also found in most popular music bands (although there are exceptions). To be a female keyboard player, then, is generally to position oneself more narrowly than in other regions of the country, in the classical music world, rather than traditional or popular music genres.

Wind, especially brass, players and percussionists, on the other hand, are well represented. In the Memorial University Folklore and Language archives, there are more female accordionists than fiddlers. Generically, the preponderance of women in classical or traditional fields is consistent with stereotypes but the number involved in blues or jazz is higher than expected, for instance, given that performance venues featuring these styles are, as yet, somewhat limited.

\section{Technology Challenges}

Technology-related challenges identified by participants in our study are consistent with many identified in other locales, and rather sadly indicative that systemic changes are not happening as rapidly as many would like to see. The Newfoundland and Labrador women represented the two relationships with technology that Judith Butler has described: "If technology is a resource to which some people want access, it is also an imposition from which others seek to be freed" $(2004,11)$. Stereotypical social expectations, processes that create feelings of fear and intimidation, patterns of dependency or invisibility, and gender-specific definitions of un/comfortable ways of working all tend to intensify the two relationships Butler articulates. But before considering issues related to new digital technologies, it is important to consider more broadly that all musical mediators (instruments, amplification systems etc.) are "technologies." The gendering we currently might identify has longer historical roots.

The binaries that have historically restricted human potential to such a large degree influence the social expectations for women who use technology, defined broadly to include musical instruments and other "tools." Perhaps the most predominant of these is the nature-culture divide. If we regard "technology" in a

\footnotetext{
4 In this regard, MUN student Fiona Rutherford's observations are interesting. In a course essay, she quotes folklorist Philip Hiscock who commented that "There seems to be a division of labour with regard to instruments, and it's connected partly to the instrument, and partly back through the instrument to the role that instrument plays in the music" $(2005,3)$. She then comments on the relative rarity of female players of guitar, bass, drums, or accordion but does not even mention keyboards, arguably indicating that keyboards are off the radar when local music is described.
} 
broad sense to include all musical instruments, including the contemporary recording studios, traces of this binary continue to map unto women and men, the former more associated with the body and song, the latter with instruments and tools. Pegley (1999) notes the rarity of women actually playing musical instruments in music videos of the mid-90s, for instance. In NL, there are similar patterns evident. In an analysis of several decades of publicity photos displayed in the Arts and Culture Centre of St. John's, Mitchell notes that women were less often photographed with an instrument until the 1990s, but further, that "there were few or no pictures of them [women] playing them." He also observes that all publicity photos with closed or hidden eyes (with sunglasses, for instance) were of men playing an instrument and seemingly "closing their eyes in the ecstasy of the musical moment (or so we are to believe)" $(2006,2)$. These images of technological use, then, repeatedly confront audiences at this venue which is the largest (except for Mile One Stadium) and arguably the most prestigious in the city of St. John's.

Feminists have done valuable work in identifying not only the instrument choices of women but the narratives that tell us how women choose specific instruments. Our questionnaire/interviews revealed some interesting patterns in the Newfoundland and Labrador community. Some women began to study instruments on the advice of teachers or parents but many had contrasting reasons. Some chose an instrument at school either to fit in or to differentiate themselves from peers. Such narratives explain how instrument choices map unto identity constructs. Some narratives of instrument choice were in the passive voice, suggesting that their instrument chose them; it felt right. The phrase, "it felt right," also indicates the value of feeling comfortable, a value that continues to inform the technology related work of women who participated in our study. The diverse narratives of instrument choice, then, often asserted strong and individualistic ways of socializing or not, even when the instruments chosen were traditionally feminized.

Historically, as is well known, Euroamerican women have been encouraged to use "tools" that they did not embrace too intimately, the piano or the sewing machine for instance. Furthermore, in the course of the $20^{\text {th }}$ century, a further strong gender divide related to electronic musical instruments. Encouragement for women to play acoustic rather than electric instruments perpetuated the tendency to downplay women's technical prowess by associating them with older "traditional" technologies. Indeed, it has only been rarely recently that electric guitar manufacturers such as Daisy Rock and Fender have targeted young women with a range of smaller necked, deeper yoked, ${ }^{5}$ and lighter weight instruments, in a wide range of colours. M.A. student Erin Sharpe conducted a research project at St. John's music shops to determine response to the Daisy Rock guitar specifically. She learned that some of the more gimmicky aspects (guitars shaped like butterflies for instance were readily recognized as poorly balanced) were not selling but that, in general, the new smaller guitars were highly regarded and popular both with young women and also some male

5 That is, shaped better for larger breasted players. 
players. The acoustic qualities but also the comfort with which the instrument could be held and manipulated were major factors. Erin, whose profile as an accomplished trumpet player and percussionist is hardly a conventional "female" one, comments on her own experience:

The idea of having a guitar to fit generally smaller women seems practical from a business point of view, and a nice boost to young girls who want to learn guitar. But I never analyzed my feelings toward my own failure to play guitar until now. It is not that my guitar was too big for me; it is that I thought that I was too small for the guitar. I did not challenge the size of the guitar as a barrier to me, but I saw it as a problem with my body and abilities. This is a world where musical objects that don't fit smaller bodies are right and the bodies that can't play them are the problem. But there is no physical reason for not having had a wider variety of guitar sizes all along. $(2006,4)$

The value of feeling comfortable, then, again emerges. But Erin's project nuances this further; women may internalize a judgment about their own bodies when technology is not comfortable.

Both at our symposium, in interviews, and in subsequent projects conducted by graduate students, the problems were clearly understood to be matters of power and agency. Indeed there are many modes of production that construct regrettably well-known patterns of dependency for women, vis a vis men. These modes include the relationship between women performers and male sound engineers, the allocation of time and credit for projects, and the language of technology.

The relationship between women performers and sound engineers who assisted the performers in preparing for performance focused in particular on the power that men had because they "set up" technology for women performers. Several stated that their reliance on men to set up their sound systems or to mix their studio recordings implied, in the minds of their male colleagues, that they (the women) were lesser musicians. The stereotyping of singers, in particular, as lesser musicians vis-à-vis instrumentalists has been described in other contexts. Thomas Porcello has cogently summed up this problem. Referring to the lone woman in a studio recording session, he notes she is "the least active member of the band in arranging [male colleague's] songs, she is rarely looked to for advice. In the highly male world of popular music, the studio and its sophisticated technologies are forcefully constructed as male domains; when women are present, it is usually as singers (background singers at that), and they are generally expected to take directions, not give them" (Porcello 2005, 284-5); compare also the technology talk of rock musicians in New York as described by Leslie Gay (2006, 214-216).

The power to "set up" for women is a tricky issue that has not often been addressed in the literature. If the genders were reversed, I'm almost sure that the set up phase would be described as part of the helping or nurturing role for women who prepare the way for successful men in the public sphere. The setting 
up for music performance, on the other hand, does not have this connotation but is rather a way of casting aspersions on the competence of women.

Setting up the technology is not a new issue but one that emerges historically in some areas of acoustic performance. In a study of women bagpipers (in St. John's, but informed by her participation in pipe bands in other Canadian locales), for instance, M.A. student Heather Wright noted the problem that women generally have because they are not taught how to set up drone pipes: "When I competed in the past, if my pipes were set up properly, I would almost always be placed in the prize list. But the fact is that I don't know how to set up my pipes. When I was growing up, my father would always do it for me, and when he wasn't around, my male pipe majors would set them up for me." She describes a performance in St. John's where two female pipers (both playing without drones because no one was available to help them set the drones up) were positioned symmetrically but in an arguably "hidden" position in the band. When she inquired about the rationale for the placement, she was told that "it balanced the two players with no drones," but she observes that a central placement of the two players would have been a still better balanced arrangement (Wright 2006, 3).

Newfoundland and Labrador women are generally vigilant about the allocation of time and attention. In our study, many singers observed that they get less sound check time than the male instrumentalists with whom they perform. My studies of indigenous sound studios revealed the same pattern. Male instrumentalists (non-indigenous, in the case of my fieldwork) were asked to do multiple takes when female (indigenous, in the case of my study) were usually recorded in one or at most two takes.

Other NL Women and Music Project participants suggested that women are given less attention more generally, often treated as "groupies" rather than bandmembers. One research consultant notes that, in a collaborative technologyintense creative project, her contribution was, in the end, not acknowledged at all.

One of the ways of maintaining the traditional power asymmetries is through the "mystification" processes, as one of our Newfoundland colleagues described them. The language of technology was a barrier for most. Gear was seen as analogous to "language," as a parallel discourse of mystification. Several musicians expressed frustration because they didn't have the language to make themselves understood when dealing with producers and sound engineers. Several reported reluctance on the part of men to share what they know or to explain the gear they are using to women. One commented that when she made her debut album, she discussed the sound she wanted with her producer, but she felt she didn't know the gear well enough to make her own decisions. ${ }^{6}$

Others feel uncomfortable with the style of discourse they encounter. The norms of technology talk, with aggressive or violent control-laden imagery,

6 According to Neil Bishop, founding director of the Recording Arts program at the College of the North Atlantic, women responded particularly well to his encouragement to experiment with microphones. The opportunity to test technology in relation to their own voices was an important means of empowerment that he gave to all students. 
have been critiqued by other scholars, most notably Andra McCartney whose analysis of professional discourse is often cited:

When I compose with recorded or synthesized sound on the computer, I work with terminology that is already inscribed with gendered (and colonial) cultural values. I use a master controller keyboard and a slave module. I capture a region in a soundfile, bang a metro, strip a note, punch in a new sound, kill an unwanted track and mix down my resulting file to virgin tape. This is the symbolic level of computer music-the language used in programs and manuals, that I see in front of me on the screen, that I want to change. (McCartney 2005a)

While the women who participated in the NL Women and Music Project were less specific about the metaphors, they represented quite well the feeling of alienation that industry language elicits.

Lest it seems that our research project participants were actually just ignorant of the technologies they use, I should mentioned that $11 \%$ of the questionnaire respondents self-identified as "technology professionals." Most of this group were among the $47 \%$ of respondents who report substantial career shifts. Through their self-definition, they constructed a rather broad definition of the category, however, including audio engineers, film editors, and CD producers with diverse types of technology training. The wide range of their definitions is reminiscent of Thomas Porcello's call to expand the concept of "sound engineering," a term that "takes on a special significance when it is moved beyond a narrow reference to the technological manipulation of sonic output" (2005, 275). The relatively small but globally ambitious community in NL thrives when people are artistic multi-taskers. The broad definition of "technology professional" reflects this. The very breadth of definition that NL women insisted upon, then, was one of the "logics of creation" that is arguably place related.

The broad definition of "technology professional" that our project participants argued for also related to the way they defined what I will call "comfort" in relation to their work with technology. Many performers and creators approached technology pragmatically, desiring only to know what they needed for specific tasks, for instance, live sound set-up or audio editing. Consistent with this pragmatism was the suggestion of one participant that training for women should be "hands on and project oriented, more of a making something, creatively engaging." I will return to this point in discussing effective strategies for change.

The issues of performers differed somewhat from those of studio creators who had acquired skills and overcome residual technophobia. They focused on access to training and on the consequent comfort in the context of their peers. They noted that their male counterparts had, from an early age, many informal venues and a great deal of peer support to learn technology skills. Women, on the other hand, are often discouraged from doing this "masculinized" play/work and hence, once they make the decision to train, they are often both older and simultaneously at an earlier stage of professional development. The pressure to acquire skills quickly is intense and the isolation they may feel in male domin- 
ated classes adds to the stress. Their comments echoed a presentation made by Lesley Howell, a recent female graduate of the Stephenville Recording Arts program, to a symposium on "Women, Music, and Technology" in St. John's in 2004. Feeling intimidated as the only girl in her class, Howell noted that while some of her male peers "had been working in the sound industry and had an extensive knowledge of sound reinforcement and equipment," some were no more knowledgeable than she was at the outset. What differed was the clear dynamic that made her feel she had to prove herself. Luckily for her, this was not a problem; she graduated with high marks and served as class president and project coordinator with Music Industry program students, the latter a job that her male students were not willing to do (Howell 2004).

Recording arts and mixing were not the only realms where intimidation was a factor for young women who sought technological proficiency. A performer (a female punk-rock musician who is now a respected recording artist) described the challenges when boys generally use electronic instruments and various technological mediators earlier than their male peers:

You don't want to be as sucky as a 16-year old boy when you're 30, but you have to! You have to go through that phase and it's really hard because at the same time as you're going through that, you also have this pressure to represent women and prove that girls don't suck-but you're not going to prove it for like five years or something.

This problem of learning an instrument at a later period than their male counterparts is exacerbated by the scarcity of keyboard players in popular or traditional music in Newfoundland and Labrador. In many other urban locales, women often train on piano early in their lives and transfer those skills to a variety of genres. In Newfoundland and Labrador, however, keyboard players who want to access the world of popular music performance generally must retrain on a different instrument.

Some project participants suggested that learning, itself, had other gendered aspects. Two instructors noted that while expectations for female students were initially not high because of their inexperience, the students quickly excelled because they were more "serious" than their male counterparts. One suggested that, in a female-only training context where she taught, there was little tolerance for anyone who arrived unprepared. This was not the case in an all-male choir that she also conducts. Hence, histories of gendered social dynamics may affect the ways in which one can and must acquire musical skills.

The technological professionals and performers shared concerns about image and the social expectations of how much control they claimed. Those who insisted on control over technology were often subject to accusations of being pushy or aggressive, beyond the bounds of acceptable "feminine" stereotypes.

Most of this is old news. Indeed, while the participants in our project were admirably articulate about the issues, the same technology related challenges for women have been articulated elsewhere. The only two matters that differed somewhat and are arguably place-dependent were the sparse opportunities for 
keyboard players and the challenges but also advantages of the small population base and close social networks that accrue from that.

This leads me, then, to consider specific strategies that women have used in NL to address their technology needs. Here, we found that place was a more significant factor. In other words, while the problems of women and technology may be systemic and similar from one North American locale to another, the strategies for addressing those problems may be most effective when they are localized and specific, when the musicians are aware of the contingencies of place.

\section{Strategies for Addressing Technology Issues}

It is important not to view technology as deterministic of the hierarchical binaries that are still evident in the social roles and gender patterns described above and paralleled in other Canadian (and international) musical communities. Rather, as Elaine Lawley has observed, users of technology have a role in shaping their environments: "....if we reshape our view of the process to see the user of technology as a subject, rather than an object, we provide an avenue for women to act as agents of change in this digital revolution, rather than ineffective objects" $(1993,10)$. With reference to Ruth Hubbard's emphasis on controlling the design of technology, Lawley emphasizes that we must not discredit the "power that women may have found in their roles as users of technology" (ibid.) She challenges us to rethink the role of the "user" in "shaping and reshaping the environmental space created in CMC systems" and urges an emphasis on training and educational programs (ibid.).

Lawley's views were paralleled by those of our symposium participants. They pointed to Newfoundland and Labrador women who were already controlling the shape of technologically mediated products, especially audio recordings. In particular, they repeatedly urged for a wider array of types and styles of technology training programs, ones that could accommodate people at different career stages and ages. ${ }^{7}$ Some instances of new programs had already been devised by women.

In addition, just as the definition of "technological professional" was broad within the group we worked with, the definition of "professional environment" was similarly open-ended. Among the effective strategies they used to control the technological tools of their art were engagement with different media networks, particularly film-makers, as well as new collaborations with one another.

\section{a) Control of technology mediated products:}

The number of women who train as sound engineers in the province is very ${ }^{l o w}{ }^{8}$ but the number who produce audio recordings and who run their own

\footnotetext{
Our questionnaire data demonstrated, as mentioned above, that $47 \%$ of women in music in the province have made quite dramatic career shifts, and these shifts often involved a need to control more or different technologies.

8 The former head of the Recording Arts program at the College of the North Atlantic didn't have statistics but said that: "We have had several women come through the program and they have done very
} 
recording companies is somewhat higher. Pamela Morgan (producer and coowner of Amber Records) and Ann Devine (producer of award-winning CDs by the Ennis Sisters) are two of the most prominent. Concerned with the artistic vision, not with who twists the knobs, Morgan emphasizes that she chooses technology collaborators who respect her musicianship. She also explains that she knows the language of technology and has become adept at explaining what she wants when working alongside a sound engineer. Her command of the communication process is, then, an effective means of taking control and achieving the artistic result she wants.

Related to having a command of the communication process is a strategy adopted by one of the female graduates of the Recording Arts program at the College of the North Atlantic. Observing that she was less oriented to hacking and more methodical about taking notes than her male colleagues, she became something of a knowledge resource for others.

A third stratagem that women have found effective is to be open to producing in styles that are outside the mainstream popular music genres. Boden Sandstrom (2000) has reported that women sound engineers in the Washington D.C. area are often preferred over their male counterparts to produce less mainstream ensembles or to work with culturally diverse musicians who may not appreciate the traditional hierarchies of the studio. Like Boden, Pamela Morgan was sought out both to arrange tracks and produce a recording of Newfoundland Mi'kmaq music from Conne River (see Diamond 2005 for a description of some of the gender issues that emerged in the process of doing this project).

\section{b) Creating Alternative Training Opportunities for Women:}

A first step toward improving the quality of one's training is to articulate one's needs. Our project participants were clear about both the type and extent of training opportunities they needed. The majority of popular music performers wanted workshops to help them set up their own live sound, to understand basic audio signal paths, to learn the best audio recording practices, to undertake digital audio editing, or to understand more about acoustics. About $10 \%$ wanted a more in-depth program on audio recording, digital notation, mixing and digital audio editing. Many emphasized the need for training programs that had flexible scheduling to accommodate people with day jobs or women with childcare responsibilities. As our research was underway, the provincial music industry association, MusicNL was planning a series of province-wide, technology training workshops for the 2006-07 season. There has not yet been opportunity to assess whether these met some of the concerns of the women who participated in the research.

Enterprising women have not waited for institutional programs, however. A success story in this regard is the St. John's "Rock School for Girls," the brain child of local musician Liz Pickard, together with co-founders Rhiannon Thomas and Cherie Pyne. Established in 2003, this was (as far as I have been able to

well" (interview with B.D. 2004). He observed that their Music Industry program was more gender balanced than the Recording Arts program. 
ascertain) the first girls-only rock school in the country. The cities of Victoria and Edmonton, both with leadership from Rachelle Van Zanten, soon followed suit with rock "camps" for girls. The Rock School's clientele of young teenagers rapidly feel empowered by such simple actions as learning how to plug their guitar into an amplifier, how to program synthesizer timbres, or multi-track their recordings. As Pickard states:

The technical aspect is a big issue and it's really such a small thing to rectify. Especially with electric equipment there is an intimidation factor for many young women (there certainly was for me) and the set up is just so simple and usually it's the only information a young woman needs-"put this cable in this hole and plug it in here"-to break down the barrier. So we go there a lot and make our workshops totally hands on. (email to B.D., July 31, 2005)

This school addresses two of the problems articulated earlier: it eliminates the intimidation factor by assuming no prior experience and by teaching in a women only environment; by targeting young teenagers, it gives women an earlier start in technology-heavy popular music genres, relative to older generations. Pickard, herself, with six CDs by her ensemble, Lizband, as well as current organizers/teachers such as Cherie Pyne and Jill Porter, each of whom released a debut CD in 2005-06, are models of success for the girls who enroll. At the same time, the teachers are sufficiently close to the beginning of their careers that they can share their struggles. The media-savvy organizers of this school have been wise in documenting their work with a video on the first Rock School, and with other video work on individual artists now posted on myspace or youtube sites.

It is interesting that such training opportunities for girls seem, so far, to thrive in small or medium sized cities where effective advertising need not be expensive: hand-made notices, word of mouth. The relative ease and economy of creating alternative projects in small centres is one of the advantages they have over the larger metropolis, albeit an advantage that may rapidly be replaced by access to internet blogs such as myspace or youtube.

\section{c) New Media Networks}

The most advanced technology users among research project participants had invariably reached across the borders of disciplines to other new media creators in dance and film or to institutions (schools, theatres, churches, but also various community venues) to find their creative niches, and often to find work as well. The sense of feeling isolated in one or another sector of the music business is clearly related to this. Arguably, that isolation is more intense in a small community or remote locales. Equally, however, the smallness and close social networks of Newfoundland and Labrador were perceived as factors that brought artists of many persuasions into easier contact with one another.

Advantageous for women in Newfoundland and Labrador are the many festivals and institutions that encourage experimental creative work in new media. Many female audio technologists gravitate to these cross-disciplinary sites. The 
Newfoundland Independent Film Cooperative (NIFCO) is one institution that has enabled women's creative work. Pickard, for instance, made documentary shorts (Even Now, 2001, and Song of Encouragement, 2001) about moments in the life of her own independent band. Lori Clarke does sound for various NIFCO (film) projects and has created electronic multimedia art that has had high profile exhibitions in the new provincial art gallery, The Rooms. She has also been active in the annual Festival of New Dance in St. John's. The biannual Sound Symposium features a wide range of extended production techniques, in sound sculptures as well as live performances, and this festival introduces the St. John's community to highly acclaimed international work in this regard. Some of the work is acoustic as in the case of new instruments introduced by Toronto composer Gayle Young. In other cases, innovative installations such as Janet Cardiff's "Forty-Part Motet," installed in 2006 at The Rooms, serve as points of discussion and inspiration for local women.

d) Collaborations with Other Women:

Collaboration is regarded by virtually anyone with whom I have spoken as a strength of the Newfoundland and Labrador music scene. Women have long taken concerted initiatives to demonstrate their strength as artists and their solidarity over a wide range of issues. Many NL Women and Music participants pointed to June Hiscock whose long advocacy on behalf of women and whose production projects, including a remarkable series of concerts and CDs named Women Jammin', were acclaimed as exemplary and transformative.

A year after the 2005 workshop on Women and Music, a number of participants have observed (informally) that the amount of collaboration among women has increased as a result of the networking opportunity our project afforded. One of the earliest initiatives that emerged from the May symposium was an invitation to two of the technological professionals to work with young women in Labrador. In several other cases, women took new initiatives to perform with one another, sharing knowledge and changing roles in relation to one another. While not always technology related, this process in itself has increased the profile as well as the confidence of the women involved; it has encouraged them to try new things and learn from one another. I am reminded of the observation that Judith Butler has made about the impact of feminist theory: "there were also new ways for women as the gifts to be getting together, new modes, poetic modes, of alliance and cultural production. We had, as it were, the outlines of the theory of patriarchy before us, and we were also intervening in it, to produce new forms of intimacy, alliance, and communicability that were outside of its terms, but were also contesting its inevitability, its totalizing claim" $(2004,208)$. The alliances and new collaborations effected in Newfoundland and Labrador as a result of bringing women together to discuss gender-related issues were small but effective ways of contesting the inevitability of patriarchy. 


\section{Place and Feminist Analysis}

Place has been frequently engaged in gender analysis on the symbolic level, often, however, in a construct that is a reductionist binary. The spheres of public and private were, in early critiques, often invoked as gendered male and female "spaces," and this division still often governs expectations for musicians' performance venues and also personal behavioural styles as this study and others demonstrate. The division of natural and cultural worlds has, as mentioned earlier, often been implicated in the ways music has been gendered. A recent articulation of this is by Australian popular music scholar, Peter Doyle who describes "echo" as a "phenomenon of the natural world," one that is "often mythologized as a disempowered (though mocking) female voice." In contrast, he sees reverberation as gendered male, a quality of built environments. "Rather than dispossessed and mocking, it is associated with seats and sites of power, with pomp and circumstance" $(2005,42)$.

Without contesting the impact of these binary constructs, I note that feminists have often challenged the sweeping symbolic patterns with ethnographic studies that look to place on a micro level. Pegley's (2000) study of the "restructuring of physical space within the classroom," a change that impacted on the negotiative styles of girls and boys as they "moved between the different music technology areas" is a good case in point. The ways we use technologies to create and socialize are very specific indeed.

This specificity is also important, in my view, when I consider how a sense of place, a sense of belonging that participants in NL Women and Music and related studies feel, impacts on their desire and mode of articulating gender and technology issues. First, it is fair to say that most participants feel that their pride in being a Newfoundland and Labrador musician and their desire to contribute to the development of music in the province is intense. Second, it is fair to say that feminism is not wholly embraced by many of the women who participated in the research described here. While all participants voluntarily came to the May workshop, filled out the questionnaire, or agreed to be interviewed, there was debate about the possibility of backlash. A few noted that my leadership of the project was useful since, as a "come-from-away" I was not expected to represent a Newfoundland and Labrador perspective. At the same time, academic intellectualizing about gender issues was felt by some participants to get in the way of getting the job and getting the job done, whatever the necessary compromises.

With regard to indigenous education, Cathryn McConaghy has articulated a parallel challenge that is apropos to the reticence of some and to all of us who engage in activist gender research: "Our challenge is to determine when a consideration of cultural difference and special needs and interests is significant and when it is not; when it will lead to greater justice or greater inequality" $(2000,15)$.

While there had been good gender practices in Newfoundland and Labrador long before the Music and Gender research project and there have been a few initiatives since, it is clear that the way forward will be a delicate and distinctly localized series of negotiations. Like the various strategies for success described 
above, new initiatives will be most successful if they draw on the strength of local social networks and values, while cutting across the disciplines, regions (both geographic and artistic), and domains of expertise.

In stating this, however, I am aware that feminism has most often criticized narrowly local studies. To return one more time to Butler, for instance:

A reductive relativism would say that we cannot speak of the human or of international human rights, since there are only and always local and provisional understandings of these terms, and that the generalizations themselves do violence to the specificity of the meanings in question. This is not my view. I'm not ready to rest there. Indeed, I think we are compelled to speak of the human, and of the international, and to find out in particular how human rights do and do not work, for example, in favour of women, of what women are and what they are not. $(2004,37)$

I hardly disagree with her. My position in this paper, however, suggests that gender issues are "glocal" to use a recent buzzword, both broader than the local and provisional, but at the same time, usefully addressed on the local level.

Among the "new logics of creation" that I queried at the outset of the article are broader boundaries for defining such things as a "technological professional," and initiatives that bring women who use music technology into new alliances with film-makers, dancers, and other new media experts. Are these local? Well to the extent that they are locally unique, the answer is "no." To the extent that they are locally contingent, the answer is clearly "yes." The size of local communities, including the the relatively small St. John's community, vis-à-vis other cities in Canada, is a major factor shaping these definitions and alliances. The spirit of cooperation and the long traditions of unaccompanied narrative song that may shape instrument (and other technology) choices to the present day are clearly related to cultural and expressive values.

The NL Women and Music study (with support from several subsequent student studies) suggests that the identification of problematic systemic issues are clearly larger than the local. These issues must, however, be complemented by the identification of effective strategies for solutions which may well be most effective when they are aware of local contingencies. Furthermore, the local positioning of the study itself, in our case a government commission of a resident "outsider" to do feminist data gathering and analysis, is a crucial thing to consider as we try to implement recommendations. While the problematic issues must be addressed in the broad terms that Butler suggests, the strategies for solutions may well be most effective when they are informed by local logics.

\section{REFERENCES}

Most interviews are referenced without identifying the interviewees since there are potential career implications.

Butler, Judith. 2004. Undoing Gender. New York: Routledge.

Doyle, Peter. 2005. Echo \& Reverb. Fabricating Space in Popular Music Recording 1900-1960. Middletown: Wesleyan University Press. 
Gay, Leslie C. 2006 <1998>. "Acting Up, Talking Tech: New York Rock Musicians and Their Metaphors of Technology." In Ethnomusicology: A Contemporary Reader, ed. Jennifer Post, 209-222. New York: Routledge.

Greene, Paul D. and Thomas Porcello, ed. 2005. Wired for Sound. Engineering and Technologies in Sonic Cultures. Middletown, CT: Wesleyan University Press.

Haraway, Donna. 1991. Simians, Cyborgs, and Women: The Reinvention of Nature. New York: Routledge.

Howell, Lesley. 2005. Presentation at a Women, Music and Technology symposium, sponsored by the Research Centre for Music, Media and Place, Memorial University.

Lawley, Elizabeth Lane. 1993. "Computers and the Communication of Gender." Accessed on-line at <http://www.itcs.com/elawley/gender.html>.

McCartney, Andra. 1995a. "Inventing Images: Constructing and Contesting Gender in Thinking About Electroacoustic Music." Leonardo Music Journal 5: 57-66.

— 1995b. "Whose Playground, Which Games, and What Rules?: Women Composers in the Digital Playground. In Proceedings of the International Computer Music Conference: Digital Playgrounds, 563-570. Banff: ICMC.

McConaghy, Cathryn. 2000. Rethinking Indigenous Education. Culturalism, Colonialism and the Politics of Knowing. Flaxton, Qld: Flaxton Press.

Mitchell, Jordan. 2006. "Arts and Culture Centre Portrait Data from the 1970s to the 1990s." Term paper for MUSIC 7007, Memorial University.

Pegley, K. 1999. "An Analysis of the Construction of National, Racial and Gendered Identities on MuchMusic (Canada) and MTV (US)." Ph.D. dissertation. York University.

- 2000. "Gender, Voice and Place: Issues of Negotiation in a 'Technology in Music Program"'. In Women and Music, ed. Pirkko Moisala and Beverly Diamond, 306-316. Urbana: University of Illinois Press.

Porcello, Thomas. 2005. "Tails Out: Social Phenomenology and the Ethnographic Representation of Technology in Music Making." In Music and Technoculture, ed. Rene Lysloff and Leslie C.Gay, 264-289. Middletown: Wesleyan University Press.

Rutherford, Fiona. 2005. "Where are the Women? A Sociological Look into Factors Affecting the Visibility of Women in Folk Music." Paper written for SOCI 3731, Memorial University.

Sandstrom, Boden. 2000. "Women Mix Engineers and the Power of Sound." In Music and Gender, ed. Pirkko Moisala and Beverley Diamond, 289-305. Urbana: University of Illinois Press.

Sharpe, Erin. 2006. "Rockin' Out." Term paper submitted for MUSIC 7007, Memorial University.

Wajcman, Judy. 1991. Feminism Confronts Technology. University Park: Pennsylvania State University Press.

Wright, Heather. 2006. "Piping in Newfoundland." Term paper submitted for MUSIC 7007, Memorial University. 


\section{APPENDIX}

Questionnaire re Women Musicians in Newfoundland and Labrador

All information that you provide will be treated as confidential. It will be used, without identifying sources, to prepare a report for the Women's Policy Office, Government of Newfoundland. You are free to leave any questions blank if you prefer not to answer them.

Name:

Mailing address:

Phone:

Email address:

I am originally from Newfoundland:

Languages I speak:

Places I have lived:

Age:

Under 20

21-30

31-40

41-50

$51-60$

Over 60

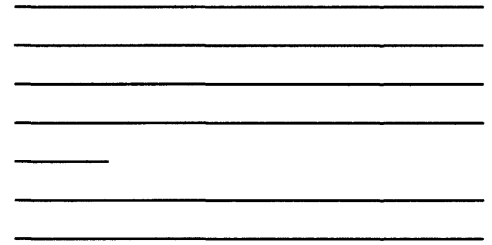

I would be willing to take part in a short telephone interview after this event.

Check all answers that apply and underline any that you regard as your primary area of professional activity.

1. Which of the following do you do?

Perform solo

Perform in a group

Accompany dance

Teach individual students

Teach in a school

Write songs or tunes

Compose classical music

Improvise

Arrange or orchestrate

Conduct choral music

Conduct instrumental music

Play or sing in church

Work as a recording arts technician

Work as a sound engineer

Do music research

Do music journalism

Work as an arts administrator

Work in theatre

Work in film

Other

2. How do you describe the style of music you do?

Pop

Rock

Punk

Country

Instrument or vocal range Group name 
Rap

Blues

Folk

Electronica

World music

Jazz

Classical

Traditional

Other (please name style or describe)

3. What music training do you have?

Taught by family or friends

College diploma

Self-taught

Individual lessons

Professional workshops

University music degree

Professional Apprenticeship

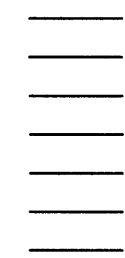

4. Is there any additional music training that you would like to have had?

5. What factors led you to do music as a profession?

Lots of music at home

Lots of music in the community

Parental encouragement

A specific teacher or mentor

Peer-group encouragement

School music environment

Church music environment

Media stars

Dreams of financial security

Dreams of getting famous

Dreams of being happy

6. How did you choose your instrument?

7. At what stage of your career are you?

Music has been a central part of my life for

I. 1-5 years

II. 6-10 years

III. $11-15$ years

IV. $16-20$ years

V. over 20 years

8. How much music do you do?

On a weekday, I do music-related activities for about

On a weekend I do music-related activities for about

I am happy with this amount of time?

Yes

Music is my primary means of employment Yes

I want music to be my primary employment. Yes hrs/day. hrs/day. No No No 
9. How well are you paid?

I have a salary for the music-related activities I do? Yes No

i. Full-time

ii. Part-time

I performed approximately during the past six months.

I have a set fee for a performance? Yes

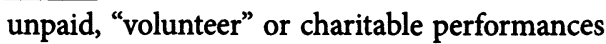
y

Amount:

The lowest fee I have received for a performance was

The highest fee I have received for a performance was

I am hired for approximately gigs during my busiest month.

10. Where do you perform?

I perform most often in the following live venue.

Last year, I also performed in the following live venues.

Last year I worked on a recording. Yes No

Studio name or location:

Last year, I toured

i. In Newfoundland or Labrador?

ii. Elsewhere in Canada?

iii. In the U.S.?

iv. In Europe?

v. In other parts of the world?

11. Do you have a media profile?

My work was aired on TV or radio last year. Yes No

I have made CDs.

My work has been published in print. Yes

No

12. What career shifts, if any, have you made?

13. Do you belong to any of the following organizations?

Registered Music Teachers Association

Music Industry Association

East Coast Music Association

Folk Arts Council

Which one?

SOCAN

Canadian Music Centre

Musicians' Union

Other (please name)

14. Do you have

An agent?

A website?

A publicity package?

15. Do you want to comment on anything else? 